Article

\title{
Synthesis of ZnO-NPs Using a Convolvulus arvensis Leaf Extract and Proving Its Efficiency as an Inhibitor of Carbon Steel Corrosion
}

\author{
Ghadah M. Al-Senani (D) \\ Department of Chemistry, College of Science, Princess Nourah Bint Abdulrahman University, \\ Riyadh 11671, Saudi Arabia; gmalsnany@pnu.edu.sa
}

Received: 15 January 2020; Accepted: 14 February 2020; Published: 17 February 2020

\begin{abstract}
This paper studies the use of zinc oxide nanoparticles (ZnO-NPs) synthesized using an extract of Convolvulus arvensis leaf and expired $\mathrm{ZnCl}_{2}$, as efficient inhibitors of carbon steel corrosion in a $1 \mathrm{M} \mathrm{HCl}$ solution. The synthesized $\mathrm{ZnO}-\mathrm{NPs}$ were characterized by Fourier-transform infrared (FTIR) and UV-Vis spectroscopy analysis. The corrosion inhibition of carbon steel in $1 \mathrm{M} \mathrm{HCl}$ was also investigated through potentiodynamic polarization, electrochemical impedance spectroscopy (EIS), and the determination of weight loss. The results show that the efficiency of the prevention increased when the concentration of $\mathrm{ZnO}-\mathrm{NPs}$ was increased to $91 \%$, and that the inhibition efficiency was still high (more than $89 \%$ ) despite decreasing at high temperatures, acting as a mixed-type inhibitor. A sample of carbon steel with a protective layer of inhibitor on top was observed during immersion in $1 \mathrm{M} \mathrm{HCl}$ for $20 \mathrm{~h}$; an increase in the charge transfer resistance $\left(\mathrm{R}_{\mathrm{ct}}\right)$ and stability of the inhibitor could be observed after $6 \mathrm{~h}$. Adsorption isotherm models demonstrated that the inhibitor adsorption mechanism on the carbon steel surface followed Langmuir rather than Freundlich and Temkin behaviors. The thermodynamic parameters showed that the adsorption process is one of mixed, spontaneous, and exothermic adsorption. The results illustrate that the ZnO-NPs were a strong inhibitor of carbon steel corrosion in acid medium. The results of scanning electron microscopy (SEM) images showed that the $\mathrm{ZnO}-\mathrm{NPs}$ formed a good protective film on the carbon steel surface.
\end{abstract}

Keywords: ZnO-NPs; corrosion; synthesis; carbon steel; convolvulus arvensis leaf extract

\section{Introduction}

Carbon steel is an engineering material that is widely used in many industrial applications including manufacturing, construction, defense, transportation, and medicine. The corrosion of carbon steel is due to chemical or electrochemical reactions with the surrounding environment, and it is a spontaneous process [1]. Hydrochloric acid is used in many metallurgical industries, oil refineries, chemical and electrochemical processes, pickling metals, and the cleaning of some devices. The high concentrations of acid can affect the equipment and devices, causing severe corrosion [2,3]; this can affect the strength of materials, the environment, and the safety of society if no precautionary measures are taken to prevent or control it [4]. The corrosion of carbon steel may be present in different forms, such as uniform corrosion, galvanic corrosion, pitting corrosion, crevice corrosion, stress corrosion cracking, erosion corrosion, and microbial corrosion, among others.

One of the many traditional techniques available for preventing or controlling the corrosion of carbon steel is the enhancement of its corrosion resistance properties, which is achieved by the application of suitable inhibitors where corrosion occurs.

Chemical inhibitors that have used to prevent corrosion include organic compounds that contain active atoms of sulfur, oxygen, and nitrogen that bond with the metal surface to form a 
protective film that prevents or reduces the persistence of corrosion. These organic compounds are expensive, toxic, and hazardous to the environment. Recently, many researchers have investigated the use of environmentally friendly inhibitors. Most natural products are nontoxic, biodegradable, and inexpensive. Plant extracts contain many organic compounds that have the ability to inhibit corrosion [5], such as been demonstrated for Bridelia ferruginea extract [6], a methanolic extract of Erigeron floribundus (Kunth) [7], an oil extract of Balanites aegyptiaca seed [8], extracts of date palm waste [9], Coriandrum sativum leaf extracts [10], watermelon rind extracts [11], Gmelina arborea bark extracts [12], loquat leaf extracts [13], borage flower extracts [14], and Chinese gooseberry fruit shell [15].

Nanotechnology is one of the most active fields of research in modern materials science. The focus of recent research has been placed on designing and developing the biochemistry of nanoparticles using many plant extracts. Typically, they contain compounds that include electron-rich atoms similar to those found in chemical corrosion inhibitors, which are also capable of forming nanoparticles of minerals that provide a greater surface area for interaction on the carbon steel surface [14].

$\mathrm{ZnO}$ is one of the most promising nanomaterials due to its thermal and mechanical stability at room temperature in addition to good physical and chemical stability [16-18], its applications in the fields of environmental treatment and corrosion protection, and its low cost [4].

There are many studies on the use of zinc oxide synthesized using polymers $[17,18]$ as corrosion inhibitors in different environments, and few studies on the synthesis of ZnO-NPs by green methods [16,19-21].

Convolvulus arvensis (field bindweed) is a plant of a wider family, which includes several species such as Convolvulus althaeoides and Convolvulus scammonia, which are annual or perennial herb vines. Convolvulus arvensis is one of the climbing plants that are currently cultivated for their aesthetic value, as it is highly prolific and able to cover large areas of building facades [22-24]. Some Convolvulus species are evergreen while some others lose their leaves seasonally; some are used in medical applications, while others are very poisonous [25].

In this study, zinc oxide was synthesized using expired zinc chloride with a Convolvulus arvensis leaf extract, and ZnO-NPs were characterized using Fourier-transform infrared (FTIR) and UV-Vis analysis. The efficacy of ZnO-NPs as an inhibitor of corrosion in carbon steel when immersed in $1 \mathrm{M} \mathrm{HCl}$ (standardized by a standard $\mathrm{NaOH}$ solution) was proved through weight loss and electrochemical measurements.

\section{Experiment}

\subsection{Materials}

All of the chemicals used in this study were of analytical grade. $\mathrm{HCl}$ ACS reagent, 37\%, expired $\mathrm{ZnCl}_{2}$ reagent grade, $98 \%$, and $\mathrm{NaOH}$ reagent grade, $97 \%$ were purchased from Sigma-Aldrich (Darmstadt, Germany).

\subsection{Preparation of the Convolvulus Arvensis Extract}

Fresh leaves from the Convolvulus arvensis leaf were collected, washed, and dried in the oven for two days at $50{ }^{\circ} \mathrm{C}$ and then cut into small pieces and stored in a glass vessel for eventual use.

The extraction was performed by adding $5 \mathrm{~g}$ of Convolvulus arvensis leaf to $100 \mathrm{~mL}$ of distilled water in a $250 \mathrm{~mL}$ conical flask and stirred for $30 \mathrm{~min}$ with heat $\left(60^{\circ} \mathrm{C}\right)$; then, the mixture was cooled and filtered through Whatman No.1 filter paper. The freshly prepared aqueous extract was used immediately after filtration.

\subsection{Synthesis of $\mathrm{ZnO}-\mathrm{NPs}$}

The extract from Convolvulus arvensis leaf $(5 \mathrm{~mL})$ was added to $45 \mathrm{~mL}$ of expired $\mathrm{ZnCl}_{2}(0.1 \mathrm{M})$ with $0.5 \mathrm{M}$ of $\mathrm{NaOH}$. The solution was stirred for $30 \mathrm{~min}$ at $50{ }^{\circ} \mathrm{C}$ leading to a change in its color, 
confirming the formation of ZnO-NPs. Then, it was separated from the solution by a centrifuge, dried, and retained for later use (Figure 1).
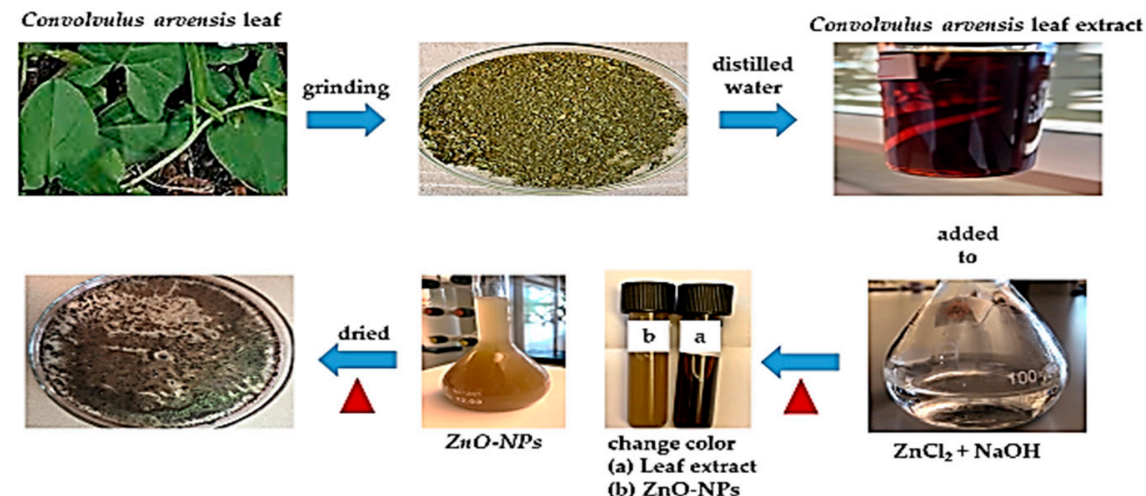

Figure 1. Synthesis of zinc oxide nanoparticles (ZnO-NPs).

\subsection{Preparation of the Test Solution}

One mole of a $1 \mathrm{M} \mathrm{HCl}$ solution was prepared by diluting $37 \% \mathrm{HCl}$ with double-distilled water. Next, $300 \mathrm{mg}$ of the ZnO-NPs powder was mixed with $100 \mathrm{~mL}$ of $1 \mathrm{M} \mathrm{HCl}$ and kept as a stock solution $(\mathrm{pH}=2.10)$. All corrosion experiments, both in the presence and absence of the inhibitor at different concentrations ranging from 0.006 to $0.12 \mathrm{mg} / \mathrm{mL}$, were carried out using this $1 \mathrm{M} \mathrm{HCl}$ solution.

\subsection{Preparation of Carbon Steel Specimens}

The sample of carbon steel used for this study was API X65 from SABIC in Saudi Arabia. The chemical composition of this carbon steel is listed in Table 1. Specimen samples were cut as cylinders with a diameter of $1 \mathrm{~cm}^{2}$ and inserted in a Teflon holder. Then, they were polished with 800,1000 , and 1500 grade emery papers, cleaned with acetone, washed with double-distilled water, and dried.

\subsection{Characterization of $\mathrm{ZnO}-\mathrm{NPS}$}

FTIR spectra were recorded for the dried nanoparticles using a Fourier-transform infrared spectrophotometer (type spectrum 100 FTIR spectrometer) over a wavenumber range of 400 to $4000 \mathrm{~cm}^{-1}$. UV-Vis analysis was carried out in the ultraviolet spectrum using a type V-770 UV-Visible/near-infrared (NIR) spectrophotometer) over a wavelength range of 200-800 nm.

\subsection{Surface Characterization}

After immersion in $1 \mathrm{M} \mathrm{HCl}$, the morphology of the carbon steel surface was studied both in the presence and absence of $0.06 \mathrm{mg} / \mathrm{mL}$ of $\mathrm{ZnO}-\mathrm{NPs}$ for $3 \mathrm{~h}$ at room temperature using a JSM-6380 LA model scanning electron microscope at a high resolution of $3.0 \mathrm{~nm}$ and an accelerating voltage of $0.5-30 \mathrm{kV}$.

\subsection{Weight Loss Method}

Carbon steel specimens were completely immersed in $50 \mathrm{~mL}$ of $1 \mathrm{M} \mathrm{HCl}$ solution without and with $0.006,0.03,0.06,0.09$, and $0.12 \mathrm{mg} / \mathrm{mL}$ of the inhibitor for $3 \mathrm{~h}$ at temperatures of 298 and $333 \mathrm{~K}$. Then, the specimens were washed, dried, and weighed. The corrosion rates $\left(C_{\text {rate }}\right)$, degree of surface coverage $(\theta)$, and the inhibition efficiency $\left(E_{\mathrm{inh}} \%\right)$ were calculated from the loss in weight using the following equations:

$$
C_{\text {rate }}=\frac{W}{A t}
$$




$$
\begin{gathered}
\theta=\frac{\left(W_{0}-W_{\text {inh }}\right)}{W_{0}} \\
E_{\text {inh }}(\%)=\frac{\left(W_{0}-W_{\text {inh }}\right)}{W_{0}} \times 100
\end{gathered}
$$

where $W$ is the weight loss of carbon steel, $\mathrm{A}\left(\mathrm{cm}^{2}\right)$ is the area of specimens, $t(\mathrm{~h})$ is the immersion time, and $W_{0}$ and $W_{\text {inh }}$ are the losses in weight $(\mathrm{mg})$ of carbon steel.

\subsection{Electrochemical Measurements}

A Gill AC apparatus was used to conduct potentiodynamic polarization and electrochemical impedance spectroscopy (EIS) measurements. All measurements were performed using three electrodes: the carbon steel electrode (working electrode), the graphite electrode (counter electrode), and the silver/silver chloride electrode (reference electrode). The working electrode was immersed in a test solution of $1 \mathrm{M} \mathrm{HCl}$ without and with $0.006,0.03,0.06,0.09$, and $0.12 \mathrm{mg} / \mathrm{mL}$ of the inhibitor at temperatures of 298 and $333 \mathrm{~K}$; the open circuit potential was measured $15 \mathrm{~min}$ after attaining a steady state. Potentiodynamic polarization measurements were conducted at a scan rate of $0.2 \mathrm{mV}$ $\mathrm{s}^{-1}$ and a range of $\pm 250 \mathrm{mV}$ with respect to its potential to corrode. The frequency range of EIS measurements was between 0.01 and $10,000 \mathrm{~Hz}$. The inhibition efficiency $\left(E_{\mathrm{inh}}(\%)\right)$ was calculated using the following equations:

$$
\begin{gathered}
\text { Potentiodynamic polarization : } E_{\mathrm{inh}}(\%)=\frac{\left(i_{\mathrm{corr}}-i_{\mathrm{corr}(\mathrm{inh})}\right)}{i_{\mathrm{corr}}} \times 100 \\
\text { EIS : } E_{\mathrm{inh}}(\%)=\frac{\left(R_{\mathrm{ct}(\mathrm{inh})}-R_{\mathrm{ct}}\right)}{R_{\mathrm{ct}(\mathrm{inh})}} \times 100
\end{gathered}
$$

where $i_{\text {corr }}$ and $i_{\text {corr(inh) }}$ are the densities of the corrosion current without and with the inhibitor, respectively, which are determined from the intercept of the cathodic and anodic Tafel slopes; and $R_{\mathrm{ct}}$ and $R_{\mathrm{ct}(\mathrm{inh})}$ respectively refer to the charge transfer resistance with and without the addition of the inhibitor.

All experiments were repeated three times with an error of \pm 0.03 .

\section{Results and Discussion}

\subsection{Characterization of $\mathrm{ZnO}-\mathrm{NPS}$}

In the FTIR and UV spectra of ZnO-NPs in Figure 2, the band at 756 and $431 \mathrm{~cm}^{-1}$, illustrated in the UV spectrum $(280 \mathrm{~nm})$, is taken as evidence of the presence of ZnO-NPs. Meanwhile, the bands at $3904,3586,3680-3190,2092$, and $1635 \mathrm{~cm}^{-1}$ were attributed to the functional groups in the Convolvulus arvensis leaf extract $[19,20]$. The broad band at $3680-3190 \mathrm{~cm}^{-1}$ was due to the functional groups $\mathrm{OH}, \mathrm{NH}_{2}, \mathrm{HO}-\mathrm{C}=\mathrm{O}, \mathrm{H}_{3} \mathrm{CO}$, and $\mathrm{CH}$, and the band vibration at a height of $2092 \mathrm{~cm}^{-1}$ consisting of the bioactive thiamine $\mathrm{N}=\mathrm{C}=\mathrm{S}$, while the band region in $1635 \mathrm{~cm}^{-1}$ is due to the presence of $\mathrm{C}=\mathrm{O}$ and $\mathrm{C}=\mathrm{N}$ bonds [26]. The presence of these functional groups contributes to the inhibition of carbon steel corrosion. 


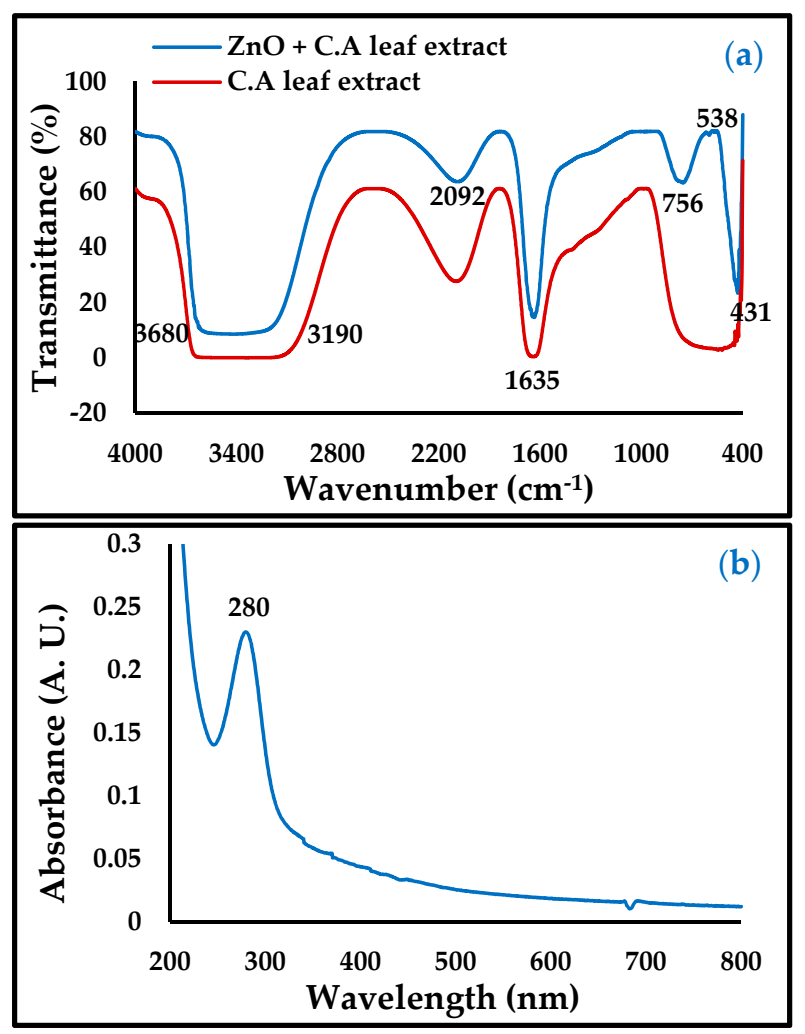

Figure 2. (a) Fourier-transform infrared (FTIR) and (b) UV-Vis of ZnO-NPs.

\subsection{Weight Loss Method}

Weight loss measurements were applied to evaluate the efficiency of the inhibitor, both in the presence and absence of different concentrations of ZnO-NPs. The carbon steel electrodes were immersed for up to $3 \mathrm{~h}$ at temperatures of either 298 and $333 \mathrm{~K}$. Figure 3 illustrates that the inhibition efficiency and degree of surface coverage increases with an increase in the inhibitor concentration and becomes stable after a concentration of $0.06 \mathrm{mg} / \mathrm{mL}$. The results are shown in Table 1 , which demonstrate that the anodic and cathodic reactions are controlled by the inhibitor molecules being adsorbed on the active sites of the carbon steel surface; thus, the surface becomes saturated with the ZnO-NPs, forming a protective layer that prevents the continuation of corrosion $[4,6,7]$.

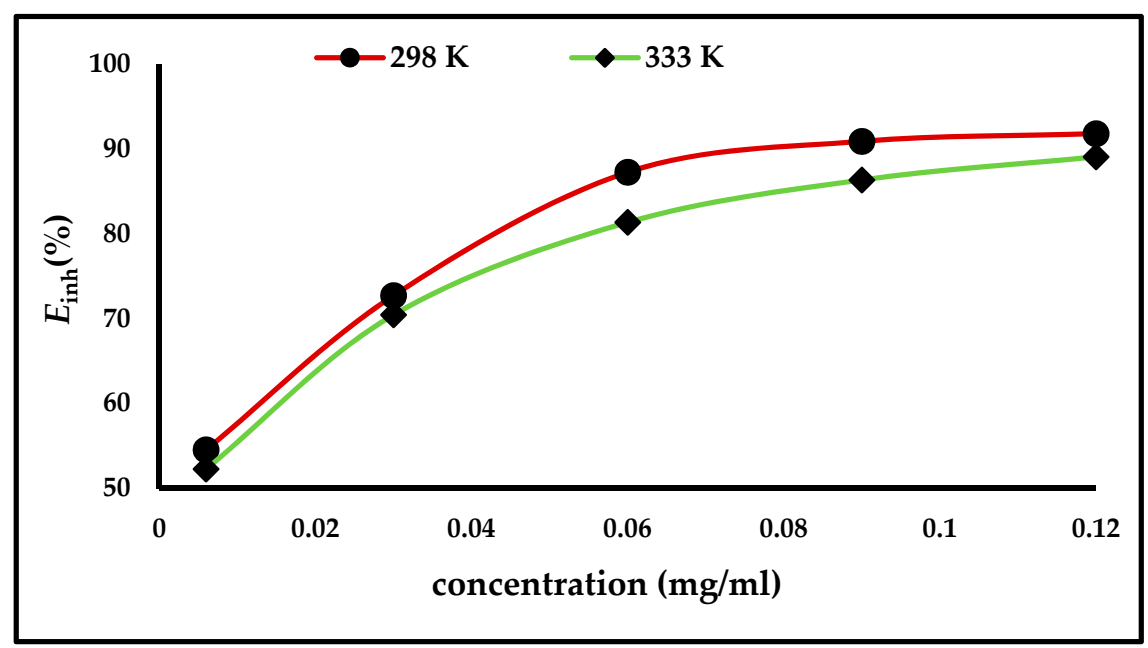

Figure 3. Effect of $\mathrm{ZnO}-\mathrm{NPs}$ concentrations on the inhibition efficiency ( $\mathrm{E}_{\mathrm{inh}} \%$ ) of carbon steel in $1 \mathrm{M}$ $\mathrm{HCl}$ at 298 and $333 \mathrm{~K}$. 
Table 1. The values of $\mathrm{C}_{\text {rate, }}$ and $\mathrm{E}_{\mathrm{inh}} \%$ for different $\mathrm{ZnO}-\mathrm{NP}$ concentrations at 298 and $333 \mathrm{~K}$ in $1 \mathrm{M}$ $\mathrm{HCl}$ solution.

\begin{tabular}{ccccccc}
\hline Temperature & \multicolumn{3}{c}{$298 \mathrm{~K}$} & \multicolumn{3}{c}{$333 \mathbf{K}$} \\
\hline $\begin{array}{c}\text { Concentration } \\
(\mathbf{m g} / \mathbf{m L})\end{array}$ & $\begin{array}{c}C_{\text {rate }} \\
\left(\mathbf{m g} / \mathbf{c m}^{2} \cdot \mathbf{h}\right)\end{array}$ & $\boldsymbol{\theta}$ & $\begin{array}{c}\boldsymbol{E}_{\text {inh }} \\
\mathbf{( \% )}\end{array}$ & $\begin{array}{c}C_{\text {rate }} \\
\left(\mathbf{m g} / \mathbf{c m}^{2} \cdot \mathbf{h}\right)\end{array}$ & $\boldsymbol{\theta}$ & $\boldsymbol{E}_{\text {inh }} \%$ \\
\hline Blank & 1.14 & - & - & 5.72 & - & - \\
0.006 & 0.52 & 0.55 & 54.55 & 2.73 & 0.52 & 52.27 \\
0.03 & 0.21 & 0.82 & 81.82 & 1.43 & 0.75 & 75.00 \\
0.06 & 0.16 & 0.86 & 86.36 & 1.07 & 0.81 & 81.36 \\
0.09 & 0.10 & 0.91 & 90.91 & 0.78 & 0.86 & 86.36 \\
0.12 & 0.09 & 0.92 & 91.82 & 0.62 & 0.89 & 89.09 \\
\hline
\end{tabular}

\subsection{Electrochemical Measurements}

\subsubsection{Potentiodynamic Polarization Measurements}

Figure 4 illustrates the potentiodynamic polarization curves for both the anodic and cathodic Tafel behavior of carbon steel corrosion in $1 \mathrm{M} \mathrm{HCl}$ in the absence and presence of different concentrations of the inhibitor at temperatures of 298 and $333 \mathrm{~K}$. The Tafel slopes show that the addition of an inhibitor influences both anodic and cathodic reactions, leading to the conclusion that the effect of ZnO-NPs inhibitors is of a mixed type. A clear displacement of the Tafel anodic and cathodic curves has been observed for increases in $\mathrm{ZnO}-\mathrm{NPs}$ concentration to $0.06 \mathrm{mg} / \mathrm{mL}$ and above, at which point the inhibition effect plateaus due to saturation of the carbon steel surface with inhibitor molecules [27]. It should be noted that as the concentration of the inhibitor increased, the rate of corrosion decreased. This means that the inhibitor has a high efficiency of $91 \%$ at a concentration of $0.12 \mathrm{mg} / \mathrm{mL}$ at $298 \mathrm{~K}$, as recorded in Table 2. The high temperature increased $i_{\text {corr }}$ [28], but the effect of the inhibitor remained the same at a temperature of $298 \mathrm{~K}$. Its effect at $333 \mathrm{~K}$ almost became constant above ZnO-NPs concentrations of $0.06 \mathrm{mg} / \mathrm{mL}$, showing that even at high temperatures [27], when the surface of the electrode is saturated with inhibitor molecules [29], the inhibition mechanism remains functional. The presence of ZnO-NPs, in addition to the molecules of the Convolvulus arvensis leaf extract on the carbon steel surface, form a protective layer that limits anodic and cathodic reactions and thus reduces the rate of corrosion [18]. 

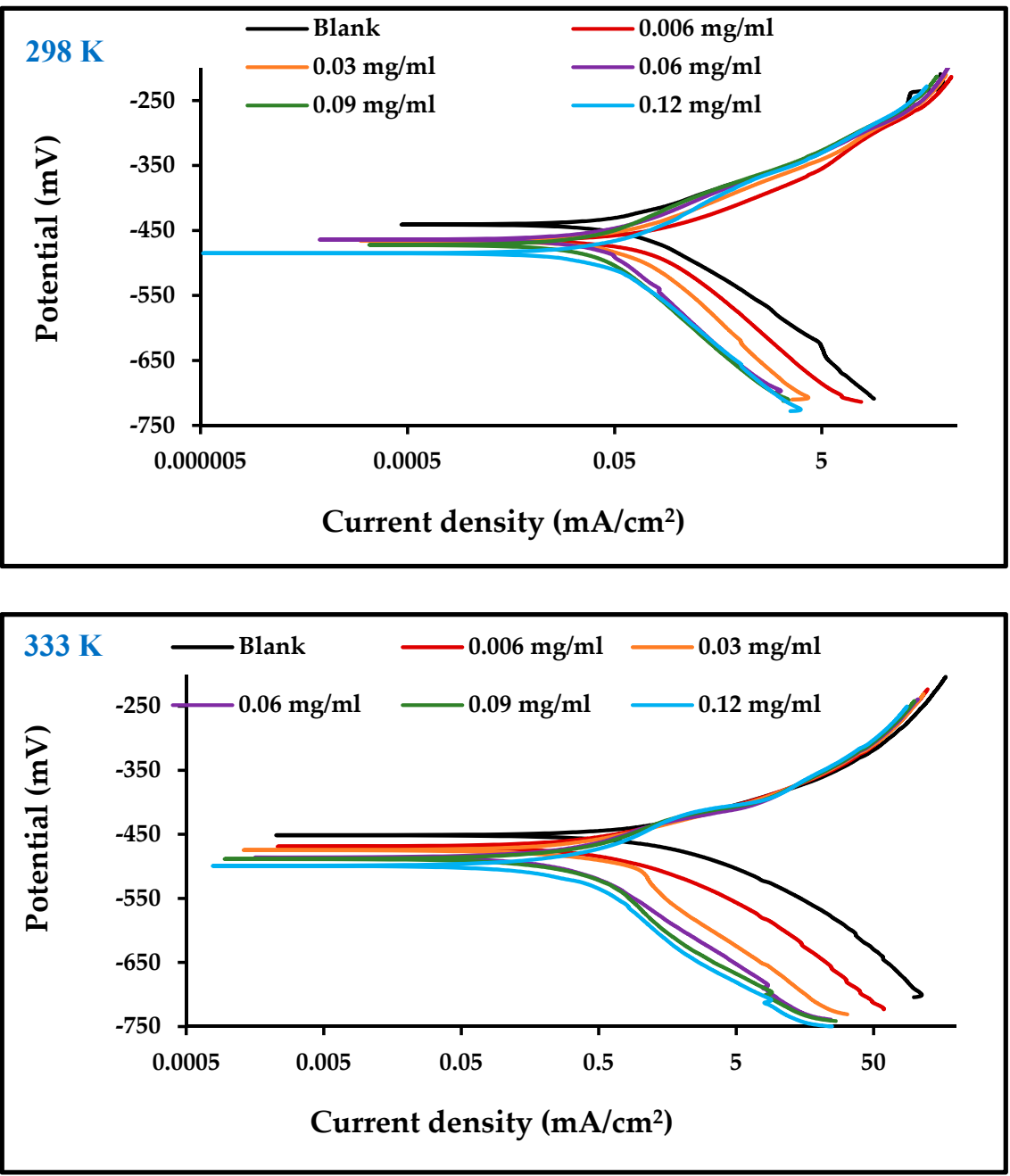

Figure 4. Polarization curves for carbon steel in $1 \mathrm{M} \mathrm{HCl}$ with and without different concentrations of ZnO-NPs at 298 and $333 \mathrm{~K}$.

Table 2. Potentiodynamic polarization parameters.

\begin{tabular}{|c|c|c|c|c|c|c|c|c|c|c|}
\hline \multirow{2}{*}{$\begin{array}{l}\text { Concentration } \\
(\mathrm{mg} / \mathrm{mL})\end{array}$} & \multicolumn{5}{|c|}{$298 \mathrm{~K}$} & \multicolumn{5}{|c|}{$333 \mathrm{~K}$} \\
\hline & $\begin{array}{l}E_{\text {corr }} \\
(\mathrm{mV})\end{array}$ & $\begin{array}{c}\beta_{\mathrm{a}} \\
(\mathrm{mV} / \mathrm{dec})\end{array}$ & $\begin{array}{c}\beta_{\mathrm{c}} \\
(\mathrm{mV} / \mathrm{dec})\end{array}$ & $\underset{\left(\mathrm{mA} / \mathrm{cm}^{2}\right)}{i_{\text {corr }}}$ & $\begin{array}{l}E_{\text {inh }} \\
(\%)\end{array}$ & $\begin{array}{l}E_{\text {corr }} \\
(\mathrm{mV})\end{array}$ & $\begin{array}{c}\beta_{\mathrm{a}} \\
(\mathrm{mV} / \mathrm{dec})\end{array}$ & $\begin{array}{c}\beta_{\mathrm{c}} \\
(\mathrm{mV} / \mathrm{dec})\end{array}$ & $\begin{array}{c}i_{\text {corr }} \\
\left(\mathrm{mA} / \mathrm{cm}^{2}\right)\end{array}$ & $\begin{array}{l}E_{\text {inh }} \\
(\%)\end{array}$ \\
\hline Blank & -441.01 & 76.90 & 123.28 & 5.15 & 0 & -451.83 & 109.87 & 150.38 & 9.93 & 0 \\
\hline 0.006 & -464.22 & 70.78 & 133.75 & 2.24 & 56.60 & -468.61 & 91.34 & 147.17 & 4.29 & 58.35 \\
\hline 0.03 & -466.08 & 69.55 & 144.68 & 1.02 & 80.17 & -480.03 & 71.25 & 145.87 & 2.37 & 77.02 \\
\hline 0.06 & -464.29 & 67.06 & 145.97 & 0.67 & 87.07 & -486.48 & 67.38 & 143.65 & 1.78 & 82.76 \\
\hline 0.09 & -473.69 & 65.83 & 147.10 & 0.50 & 90.39 & -491.62 & 66.73 & 137.29 & 1.39 & 86.55 \\
\hline 0.12 & -484.89 & 68.11 & 136.95 & 0.45 & 91.26 & -511.89 & 64.75 & 132.25 & 1.09 & 89.47 \\
\hline
\end{tabular}

\subsubsection{Electrochemical Impedance Measurements}

Figure 5 illustrates the results of an electrochemical impedance technique to determine the corrosion behavior of carbon steel in $1 \mathrm{M} \mathrm{HCl}$ in the absence and presence of $\mathrm{ZnO}-\mathrm{NPs}$ at temperatures of 298 and $333 \mathrm{~K}$ using electrochemical impedance spectroscopy (EIS). On the Nyquist diagram of $1 \mathrm{M} \mathrm{HCl}$ compared with different concentrations of ZnO-NPs and blank solution, it can be seen that all curves follow the behavior of the blank solution. The electrochemical impedance diagram shows the presence of a semicircle of small diameter in the blank solution that increases with increasing concentrations of the inhibitor. This means that the corrosion mechanism is not altered by the inhibitor [30]. The results in Table 3 show that the double-layer capacity $\left(C_{\mathrm{dl}}\right)$ decreased with an 
increase in the inhibitor concentration, while the charge transfer resistance $\left(R_{\mathrm{ct}}\right)$ increased with an increase in inhibitor concentration, and the corrosion rate became very low compared to the blank solution even at low concentrations. This shows that the inhibitor has a strong influence on the corrosion of carbon steel [31]. The Bode and phase angle diagrams showed increased area under the curves in the presence of the inhibitor compared to a blank solution. The corrosion resistance may be significantly increased with an increase in inhibitor concentrations [18]. The increase in $R_{\mathrm{ct}}$ and the decrease in $C_{\mathrm{dl}}$ with the increase in inhibitor concentration is due to the decrease in dielectric constant and/or increase in the thickness of the electrical double layer, which indicates that the ZnO-NPs act through an adsorption mechanism at the interface of the carbon steel/HCl solution [17]. This can be explained by substitution of the water molecules in the double layer with adsorbed ZnO-NPs, which form a protective film on the surface of the metal and thus decrease the dissolution of carbon steel [32]. Adsorption can also occur by giving or sharing non-participating electron pairs from the inhibitor molecule with the vacant orbitals on the carbon steel surface, or by bonding the inhibitor particles with the adsorption chloride ions on the carbon steel surface $[4,30]$. The equivalent circuit shown in Figure 6 was used for all EIS spectra; it has good compatibility with the experimental data.

The inhibition efficiency values obtained from the weight loss, potentiodynamic polarization, and electrochemical impedance measurements show good agreement with each other.
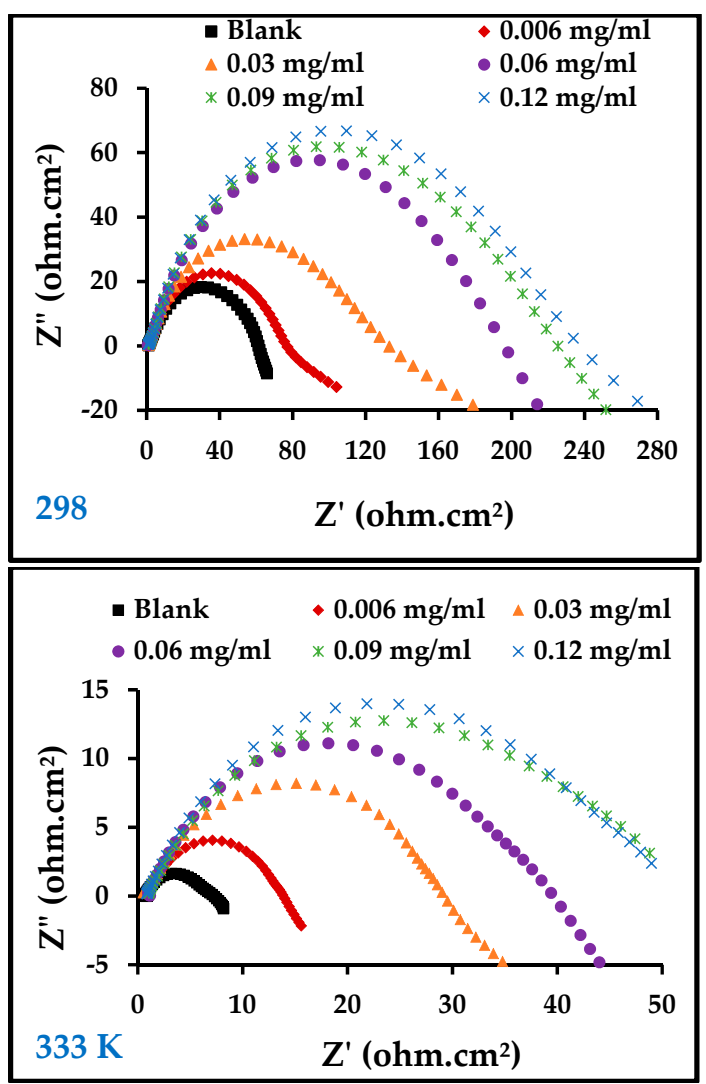

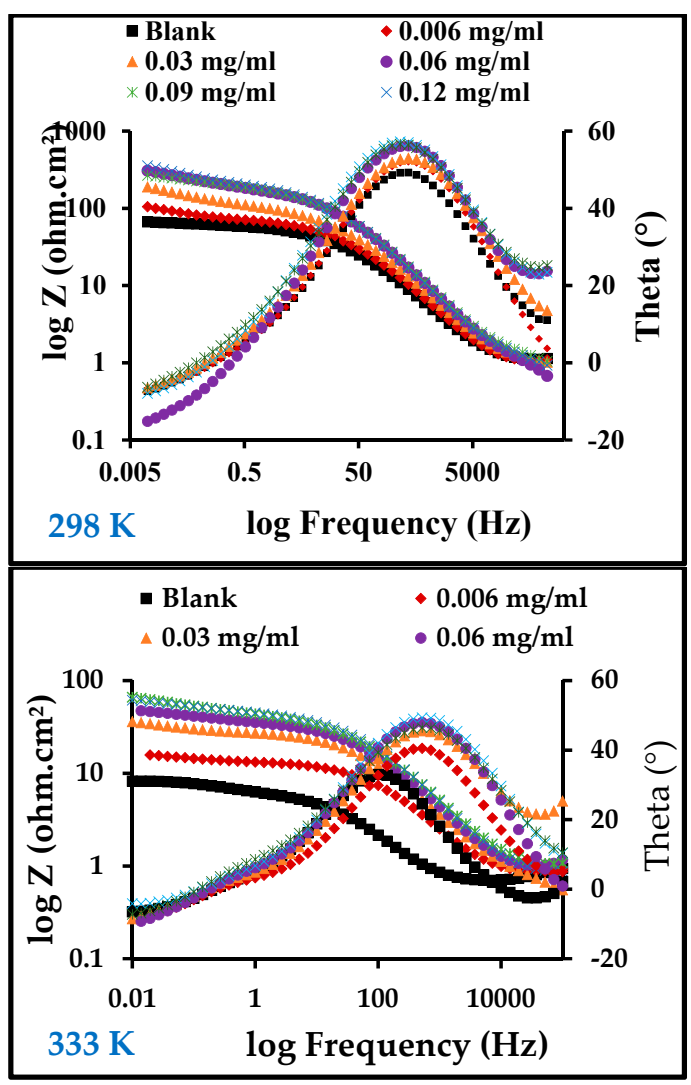

Figure 5. Electrochemical impedance spectroscopy (EIS) diagrams for carbon steel in $1 \mathrm{M} \mathrm{HCl}$ with and without different concentrations of ZnO-NPs at 298 and $333 \mathrm{~K}$. 


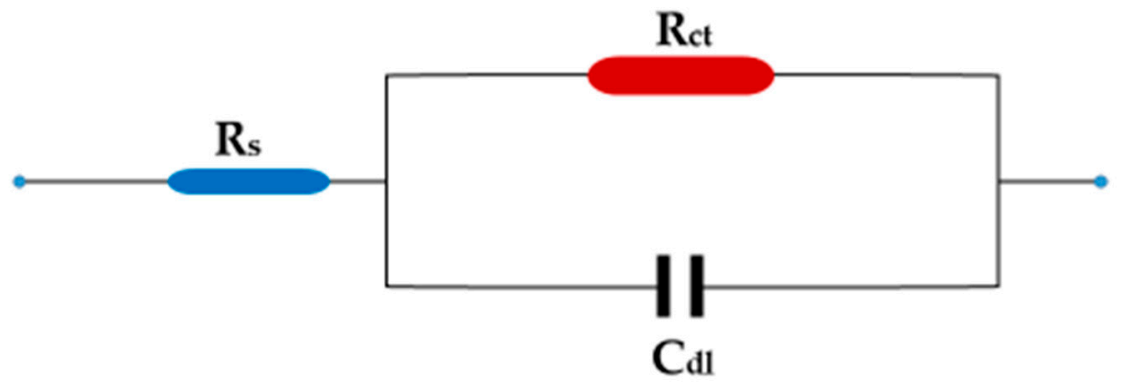

Figure 6. Equivalent circuit.

Table 3. EIS parameters.

\begin{tabular}{|c|c|c|c|c|c|c|}
\hline \multirow[b]{2}{*}{ Concentration $(\mathrm{mg} / \mathrm{mL})$} & \multicolumn{3}{|c|}{$298 \mathrm{~K}$} & \multicolumn{3}{|c|}{$333 \mathrm{~K}$} \\
\hline & $\underset{\left(\mathrm{ohms} \cdot \mathrm{cm}^{2}\right)}{R_{\mathrm{ct}}}$ & $\begin{array}{c}C_{\mathrm{dl}} \\
(\mathrm{mF})\end{array}$ & $\begin{array}{l}E_{\text {inh }} \\
(\%)\end{array}$ & $\underset{\left(\mathrm{ohms} \cdot \mathrm{cm}^{2}\right)}{R_{\mathrm{ct}}}$ & $\begin{array}{c}C_{\mathrm{dl}} \\
(\mathrm{mF})\end{array}$ & $\begin{array}{c}E_{\text {inh }} \\
(\%)\end{array}$ \\
\hline Blank & 21.55 & 0.56 & - & 5.73 & 7.33 & - \\
\hline 0.006 & 55.48 & 0.47 & 61.16 & 12.58 & 1.00 & 54.45 \\
\hline 0.03 & 127.00 & 0.43 & 81.26 & 27.86 & 0.85 & 79.43 \\
\hline 0.06 & 191.30 & 0.36 & 88.73 & 35.61 & 0.63 & 83.91 \\
\hline 0.09 & 220.10 & 0.36 & 90.21 & 45.34 & 0.54 & 87.36 \\
\hline 0.12 & 226.70 & 0.30 & 90.49 & 59.48 & 0.52 & 90.37 \\
\hline
\end{tabular}

\subsubsection{Effect of Immersion Time}

EIS was applied to determine the stability of ZnO-NPs with immersion time. The EIS technique studies the resistance of an electrode to corrosion without any influence on its behavior; hence, it is considered an appropriate technique for testing the immersion time. In Figure 7, we observe the response of steel to corrosion in $1 \mathrm{M}$ of $\mathrm{HCl}$ in the presence of $0.06 \mathrm{mg} / \mathrm{mL}$ of the $\mathrm{ZnO}-\mathrm{NPs}$ at different immersion durations at a temperature of $298 \mathrm{~K}$. It is clear from Figure 5 that the increase in immersion time does not affect the mechanism of the corrosion process [33]. It was observed that the diameter of the semicircle in the Nyquist plots increases with an increase in immersion time. The important EIS parameters are listed in Table 4 , which make it clear that $R_{\mathrm{ct}}$ increases with an increased immersion time, indicating a decreased corrosion rate. Thus, the prolonged immersion time increases the adsorption of $\mathrm{ZnO}-\mathrm{NPs}$ molecules on the carbon steel surface, ensuring its stability. It was observed that the surface coverage became stable after approximately 6 hours $[34,35]$.

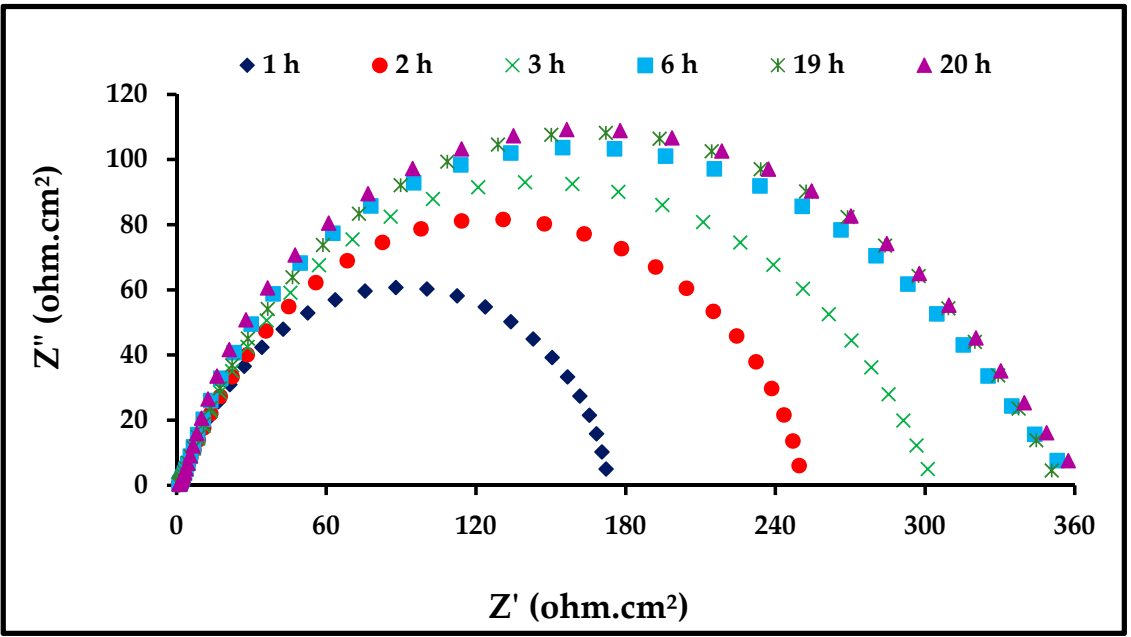

Figure 7. Nyquist plots for carbon steel in $1 \mathrm{M} \mathrm{HCl}$ with $6 \mathrm{mg} / \mathrm{mL}$ of $\mathrm{ZnO}-\mathrm{NPs}$ at $298 \mathrm{~K}$. 
Table 4. EIS parameters.

\begin{tabular}{ccc}
\hline $\begin{array}{c}\text { Time } \\
\text { (h) }\end{array}$ & $\begin{array}{c}\boldsymbol{R}_{\mathbf{c t}} \\
\left(\mathbf{o h m s} \cdot \mathbf{c m}^{\mathbf{2}}\right)\end{array}$ & $\begin{array}{c}\boldsymbol{C}_{\mathrm{dl}} \\
(\mathbf{m F})\end{array}$ \\
\hline 1 & 200.0 & 0.53 \\
2 & 276.4 & 0.49 \\
3 & 302.0 & 0.32 \\
6 & 343.4 & 0.30 \\
19 & 353.0 & 0.29 \\
20 & 359.3 & 0.28 \\
\hline
\end{tabular}

\subsection{Adsorption Isotherm Models and Thermodynamic}

Various adsorption isotherm models, such as Langmuir, Freundlich, and Temkin models, were used to ascertain information about the type of reactions that occurred between the carbon steel surface and the adsorbent molecules of the inhibitor, adsorption equilibrium constant, and surface coverage.

The degree of surface coverage was determined from the data of potentiodynamic polarization. The following equations for adsorption isotherm models were applied to obtain the linear relationship between the degree of surface coverage $(\boldsymbol{\theta})$ and inhibitor concentration $\left(\boldsymbol{C}_{\text {inh }}\right)[36,37]$ :

$$
\begin{gathered}
\text { Langmuir : } \frac{C_{i n h}}{\theta}=\frac{1}{K_{a d s}}+C_{i n h} \\
\text { Freundlich : } \ln \theta=\ln K_{a d s}+\frac{1}{n} \ln C_{i n h} \\
\text { Temkin : } \theta=\frac{-\ln K_{a d s}}{2 a}-\frac{\ln C_{i n h}}{2 a}
\end{gathered}
$$

where $K_{a d s}$ is the adsorption equilibrium constant; $a$ is the molecular reaction constant that attracts forces if the value is positive and repulses if it is negative; and $\mathrm{n}$ is a measure of adsorption intensity, where if the value of $1 / \mathrm{n}$ lies between 0 and 1 , the inhibitor molecules are easily adsorbed on the carbon steel surface is easily, while if it is equal to 1 , it is moderate, and a value greater than 1 shows that this is difficult.

The adsorption isotherm plots are presented in Figure 8, and the linear relationship and parameters obtained from those plots are listed in Table 5. The Langmuir isotherm model had the best fit when compared to Freundlich and Temkin, where the correlation coefficient $\left(R^{2}\right)$ was close to unity. The values of $\mathrm{K}_{\mathrm{ads}}$ for Langmuir and Freundlich decrease with an increase in temperature, indicating that the adsorption process slows down with an increase in temperature and is unfavorable at higher temperatures. The $\mathrm{K}_{\mathrm{ads}}$ for Temkin increases with an increase in temperature and suggests that the adsorption of the inhibitor on the metal surface at higher temperatures was due to physical adsorption [8,38].

Moreover, $K_{a d s}$ is also used to calculate the values of the standard Gibbs free energy $\left(\Delta G^{\circ}\right.$ ads $)$ according to the equation given below [9]:

$$
\Delta G_{a d s}^{\circ}=-R T \ln \left(55.5 K_{a d s}\right)
$$

where $\mathrm{R}$ is the universal gas constant, $\mathrm{T}$ is the absolute temperature, and 55.5 is the molar heat of water adsorption. The negative $\Delta G^{\circ}$ ads values in Table 2 show that the adsorption of ZnO-NPs on carbon steel surfaces is highly spontaneous at high temperatures. The values of $\Delta G^{\circ}$ ads are between -20 and -41 $\mathrm{kJ} / \mathrm{mol}$ in the Langmuir and Temkin isotherm models, which meant that both chemical and physical adsorption (mixed adsorption) occurred on the carbon steel surface. Meanwhile, it was lower than $-20 \mathrm{~kJ} / \mathrm{mol}$ in the Freundlich isotherm model, which meant that the adsorption of ZnO-NPs onto the surface of carbon steel was a physical adsorption process [9,39]. In general, values of $\Delta G^{\circ}$ ads less than $-20 \mathrm{~kJ} / \mathrm{mol}$ correspond to electrostatic reactions between the inhibitor molecules and the carbon steel 
surface (physisorption). Similarly, values that are lower than $-40 \mathrm{~kJ} / \mathrm{mol}$ involve sharing the charge or transfer from inhibitor molecules to the carbon steel surface to form a coordinate bond (chemisorption).

The adsorption enthalpy $\left(\Delta H^{\circ}\right.$ ads $)$ and the adsorption entropy $\left(\Delta S^{\circ}\right.$ ads $)$ for ZnO-NPs adsorbed on the carbon steel surface were calculated from the Gibbs-Helmholtz and Gibbs free energy equations $[10,11]$ :

$$
\begin{gathered}
\frac{\Delta G^{\circ} \text { ads }}{T_{2}}-\frac{\Delta G^{\circ} \text { ads }}{T_{1}}=\Delta H^{\circ} \text { ads }\left(\frac{1}{T_{2}}-\frac{1}{T_{1}}\right) \\
\Delta G^{\circ}{ }_{a d s}=\Delta H^{\circ}{ }_{a d s}-T \Delta S^{\circ}{ }_{a d s} .
\end{gathered}
$$

The values of $\Delta H^{\circ}$ ads and $\Delta S^{\circ}$ ads are listed in Table 5. The negative values of $\Delta S^{\circ}$ ads are an indication that the corrosion process is controlled by an activation complex [10-12,32]. The negative value of enthalpies $\Delta \boldsymbol{H}^{\circ}$ ads reflect the exothermic behavior of the inhibitor on the carbon steel surface in the Langmuir and Freundlich isotherms, but this value is positive for the Temkin isotherm; moreover, the positive value of $\Delta H^{\circ}$ ads reflects the fact that the adsorption process is endothermic [10].
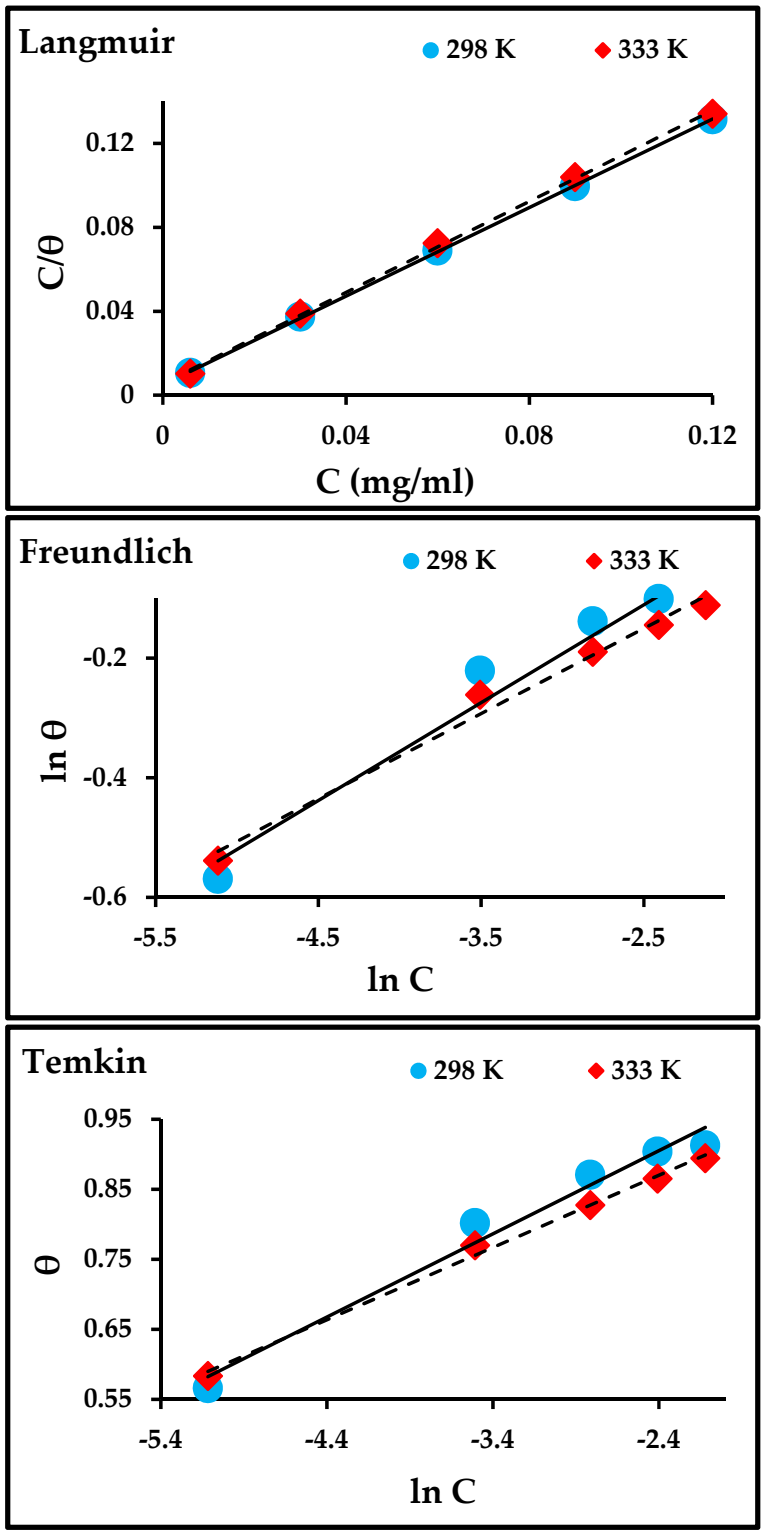

Figure 8. Langmuir, Freundlich, and Temkin isotherms for the adsorption of ZnO-NPs molecules on the surface of carbon steel. 
Table 5. Adsorption isotherm parameters.

\begin{tabular}{|c|c|c|c|c|c|c|c|c|}
\hline $\begin{array}{l}\text { Isotherm } \\
\text { Models }\end{array}$ & $\begin{array}{l}\text { Temperature } \\
\text { (K) }\end{array}$ & $K_{\mathrm{ads}}$ & $R^{2}$ & $n$ & $a$ & $\begin{array}{c}\Delta G^{\circ} \text { ads } \\
(\mathrm{kJ} / \mathrm{mol})\end{array}$ & $\begin{array}{c}\Delta H^{\circ} \text { ads } \\
(\mathrm{kJ} / \mathrm{mol})\end{array}$ & $\begin{array}{c}\Delta S^{\circ} \text { ads } \\
(\mathrm{J} / \mathrm{mol} \mathrm{K})\end{array}$ \\
\hline \multirow{2}{*}{ Langmuir } & 298 & 200 & 0.9998 & - & - & -23.0778 & \multirow{2}{*}{-2.66} & \multirow{2}{*}{-68.51} \\
\hline & 333 & 178.57 & 0.9989 & - & - & -25.4746 & & \\
\hline \multirow{2}{*}{ Freundlich } & 298 & 1.35 & 0.9604 & 0.164 & - & -10.6899 & \multirow{2}{*}{-2.15} & \multirow{2}{*}{-28.65} \\
\hline & 333 & 1.23 & 0.9862 & 0.143 & - & -11.6902 & & \\
\hline \multirow{2}{*}{ Temkin } & 298 & $22,324.87$ & 0.9766 & - & 4.205 & -34.7599 & \multirow{2}{*}{19.22} & \multirow[b]{2}{*}{-181.15} \\
\hline & 333 & $50,633.28$ & 0.9955 & - & -4.845 & -41.1097 & & \\
\hline
\end{tabular}

\subsection{Scanning Electron Microscopy (SEM) and Energy-Dispersive X-Ray Spectroscopy (EDS)}

The carbon steel surface was studied by a scanning electron microscope and energy-dispersive spectroscopy after immersion for $3 \mathrm{~h}$ in $1 \mathrm{M} \mathrm{HCl}$ solution in the absence and presence of $0.06 \mathrm{mg} / \mathrm{mL}$ of $\mathrm{ZnO}-\mathrm{NPs}$. Figure 9a,b illustrates that the carbon steel in the blank solution was highly corroded, as cracks and pits appeared on the surface along with scratches, while in the presence of an inhibitor, corrosion was prevented and the surface was free of pits and cracks, and very few scratches were present $[39,40]$. Deposits of ZnO-NPs were also observed on the surface, resulting in the formation of a protective film on the carbon steel surface. Hence, $\mathrm{ZnO}$-NPs are an effective inhibitor of corrosion in carbon steel exposed to $\mathrm{HCl}$ solution. Figure $9 \mathrm{c}$ shows that the presence of the signals of $\mathrm{O}, \mathrm{Zn}$, and $\mathrm{C}$ atoms indicate the effect of the inhibitor on the carbon steel surface, and they also prove the binding of $\mathrm{ZnO}$ and Convolvulus arvensis leaf extract with cathodic and anode active sites on the carbon steel surface [34]. The low signal of $\mathrm{O}$, high signal of $\mathrm{Fe}$, and more than one signal of $\mathrm{Zn}$, in addition to the carbon signal, indicate a high inhibitor efficiency in reducing the corrosion rate and protecting the carbon steel surface [41].
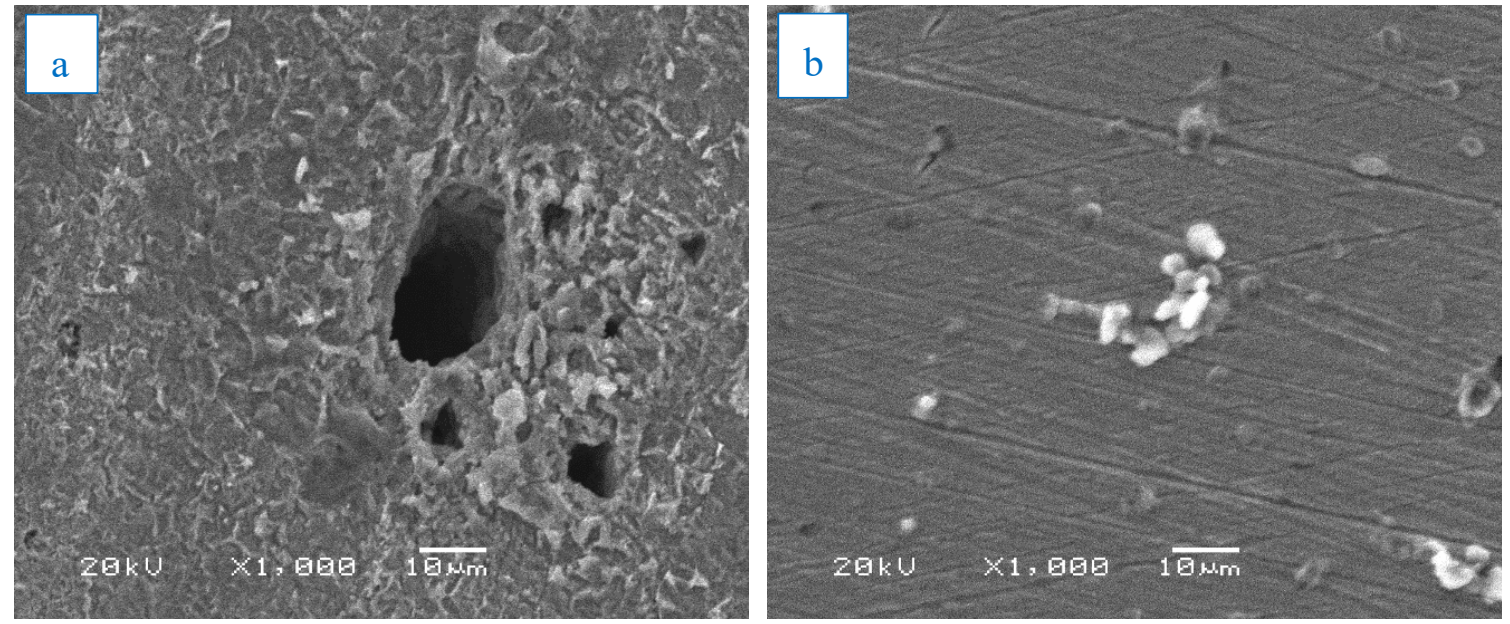

Figure 9. Cont. 


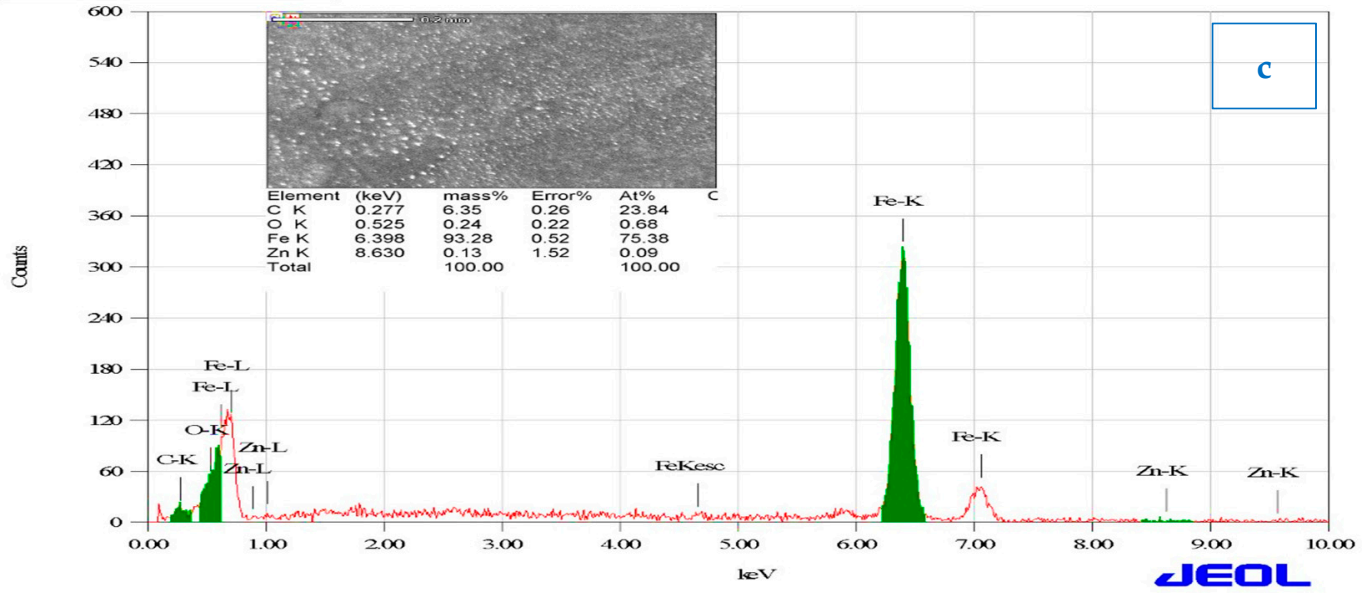

Figure 9. SEM and energy-dispersive spectroscopy (EDS) images of carbon steel immersed in (a) $1 \mathrm{M}$ $\mathrm{HCl}$ and $(\mathbf{b}, \mathbf{c})$ also in the presence of $0.06 \mathrm{mg} / \mathrm{ml}$ of ZnO-NPs for $3 \mathrm{~h}$ at $298 \mathrm{~K}$.

\subsection{Mechanism of Corrosion Inhibition}

$\mathrm{ZnO}-\mathrm{NPs}$ and Convolvulus arvensis leaf extract dissolved in $\mathrm{HCl}$ are transported toward the carbon steel surface, where $\mathrm{Fe}^{2+}$ cations and $\mathrm{H}^{+}$ions are produced on the anodic and cathodic active sites, respectively:

$$
\begin{gathered}
\mathrm{Fe} \rightarrow \mathrm{Fe}^{2+}+2 \mathrm{e}^{-} \text {(anodic reaction) } \\
2 \mathrm{H}^{+}+2 \mathrm{e}^{-} \rightarrow \mathrm{H}_{2} \text { (cathodic reaction). }
\end{gathered}
$$

In addition, the dissolved oxygen in $\mathrm{HCl}$ solution exposed to the atmosphere reduction to water, as follows:

$$
\mathrm{O}_{2}+4 \mathrm{H}^{+}+4 \mathrm{e}^{-} \rightarrow 2 \mathrm{H}_{2} \mathrm{O} \text { (cathodic reaction). }
$$

The functional groups in Convolvulus arvensis leaf extract, which include $\mathrm{O}, \mathrm{C}$, and $\mathrm{N}$ atoms, interact with $\mathrm{ZnO}$ and $\mathrm{Fe}^{2+}$, forming a complex on the interface of the carbon steel/ $\mathrm{HCl}$ solution, as follows:

$$
\mathrm{Fe}^{2+}+\mathrm{ZnO}-\text { Convolvulus arvensis leaf extract complex. }
$$

This complex occupies the active anodic sites, and reduces the corrosion rate [34,42].

Generally, the adsorption mechanism of the inhibitor molecules on the carbon steel surface is as follows:

- The inhibitor molecules are adsorbed onto the carbon steel surface by electrostatic interaction between the electrons adsorbed on the carbon steel surface (physical adsorption).

- The presence of heteroatoms having free electron pair enhances the chemical adsorption.

- The carbon steel surface becomes more negative for the accumulation of electrons on it.

This contributes to the transfer of electrons from the $\mathrm{d}$ orbitals of Fe to the non-bonding $\pi$ orbitals in the inhibitor molecules, thereby enhancing the inhibitor adsorption on the surface of the carbon steel $[16,43]$.

\section{Conclusions}

ZnO-NPs can be prepared by synthesis using expired $\mathrm{ZnCl}_{2}$ and Convolvulus arvensis leaf extract. The results obtained from the methods of weight loss, potentiodynamic polarization, and EIS measurements demonstrated that $\mathrm{ZnO}-\mathrm{NPs}$ in addition to presence of $\mathrm{N}, \mathrm{O}, \mathrm{C}$, and $\mathrm{S}$ atoms in functional groups of Convolvulus arvensis leaf extract are an effective inhibitor of carbon steel corrosion in $1 \mathrm{M}$ $\mathrm{HCl}$. The inhibition efficiency increases with increasing ZnO-NPs concentration and decreases at 
higher temperatures. It was found that the inhibition efficiency was more than $91 \%$ at $298 \mathrm{~K}$ and $89 \%$ at $333 \mathrm{~K}$; thus, it also works as a mixed-type inhibitor. The prolonged immersion time increases the adsorption of ZnO-NPs molecules on the carbon steel surface, and the surface coverage became stable after approximately $6 \mathrm{~h}$ as the $R_{\mathrm{ct}}$ value increased from 200 to $359.3 \mathrm{ohms. \textrm {cm } ^ { 2 }}$, after which it stabilized. The process of carbon steel corrosion inhibition followed the Langmuir isotherm $\left(\mathrm{R}^{2}=0.999\right)$ more closely than Freundlich $\left(R^{2}=0.960\right)$ and Temkin $\left(R^{2}=0.976\right)$ isotherms. The calculated values for $\Delta G^{\circ}$ ads, $\Delta H^{\circ}$ ads, and $\Delta S^{\circ}$ ads showed that the adsorption process was spontaneous and exothermic, and that inhibitor molecules adsorbed onto the surface of the metal as a result of the chemisorption mechanism through heteroatoms having a free electron pair, and the physisorption mechanism through electrostatic interaction between the electrons adsorbed on the surface of the carbon steel. The results of the SEM and ESD studies revealed that the ZnO-NPs can act as an effective inhibitor of carbon steel corrosion in $1 \mathrm{M} \mathrm{HCl}$ solutions, where the formation of a complex of $\mathrm{Fe}^{2+}+\mathrm{ZnO}-$ Convolvulus arvensis leaf extract on the interface of the carbon steel/ $\mathrm{HCl}$ solution reduces the corrosion rate.

Funding: This research received no external funding.

Acknowledgments: This study was supported by Princess Nourah Bint Abdulrahman University, as a part of the faculty member sabbaticals.

Conflicts of Interest: The author declare that there are no conflicts of interest regarding the publication of this article.

\section{References}

1. Tang, L.; Li, X.; Lau, S.P.; Li, L.; Mu, G.; Liu, G. A Kinetic Model to Study the Corrosion Inhibition of 500 $\mu \mathrm{M}$ PAR for Steel Corrosion in 0.5-3.0 M Hydrochloric Acid. Recent Patents Corros. Sci. 2011, 1, 56-62. [CrossRef]

2. Fouda, A.E.A.E.S.; Megahed, H.E.; Fouad, N.; Elbahrawi, N.M. Corrosion Inhibition of Carbon Steel in $1 \mathrm{M}$ Hydrochloric Acid Solution by Aqueous Extract of Thevetia peruviana. J. Bio- Tribo-Corrosion 2016, 2, 16. [CrossRef]

3. Saeed, M.; Saleem, M.; Usmani, S.; Malik, I.A.; Al-Shammari, F.A.; Deen, K.M. Corrosion inhibition of mild steel in $1 \mathrm{M} \mathrm{HCl}$ by sweet melon peel extract. J. King Saud Univ. Sci. 2019, 31, 1344-1351. [CrossRef]

4. Sliem, M.H.; Afifi, M.; Radwan, A.B.; Fayyad, E.M.; Shibl, M.; Heakal, F.E.-T.; Abdullah, A.M. AEO7 Surfactant as an Eco-Friendly Corrosion Inhibitor for Carbon Steel in $\mathrm{HCl}$ solution. Sci. Rep. 2019, 9, 2319. [CrossRef]

5. Bouanis, M.; Tourabi, M.; Nyassi, A.; Zarrouk, A.; Jama, C.; Bentiss, F. Corrosion inhibition performance of 2,5-bis(4-dimethylaminophenyl)-1,3,4-oxadiazole for carbon steel in $\mathrm{HCl}$ solution: Gravimetric, electrochemical and XPS studies. Appl. Surf. Sci. 2016, 389, 952-966. [CrossRef]

6. Ijuo, G.; Chahul, H.; Eneji, I. Kinetic and Thermodynamic Studies of Corrosion Inhibition of Mild Steel using Bridelia ferruginea Extract in Acidic Environment Kinetic and Thermodynamic Studies of Corrosion Inhibition of Mild Steel using Bridelia ferruginea Extract in Acidic Environment. J. Adv. Electrochem. 2016, 2, 107-112.

7. Abeng, F.; Idim, V.; Nna, P. Kinetics and Thermodynamic Studies of Corrosion Inhibition of Mild Steel Using Methanolic Extract of Erigeron floribundus (Kunth) in $2 \mathrm{M} \mathrm{HCl}$ Solution. World News of Nat. Sci. 2017, 10, 26-38.

8. Iroha, N.; Hamilton-Amachree, A. Inhibition and adsorption of oil extract of Balanites aegyptiaca seeds on the corrosion of mild steel in hydrochloric acid environment. World Sci. News 2019, 126, 183-197.

9. Al-Senani, G. Department of Chemistry, College of Science, Princess Nourah bint Abdulrahman University, Riyadh, Saudi Arabia Study the Corrosion Inhibition of Carbon Steel in $1 \mathrm{M} \mathrm{HCl} \mathrm{Using} \mathrm{Extracts} \mathrm{of} \mathrm{Date}$ Palm Waste. Int. J. Electrochem. Sci. 2018, 13, 3777-3788. [CrossRef]

10. AL-Senani, G.; AL-Saeedi, S.; AL-Mufarij, R. Coriandrum sativum leaves extract (CSL) as an eco-friendly green inhibitor for corrosion of carbon steel in acidic media. J. Mater. Environ. Sci. 2016, 7, 2240-2251.

11. Odewunmi, N.; A Umoren, S.; Gasem, Z. Utilization of watermelon rind extract as a green corrosion inhibitor for mild steel in acidic media. J. Ind. Eng. Chem. 2015, 21, 239-247. [CrossRef]

12. Nnanna, L.; Uchendu, K.; Nwosu, F.; Ihekoronye, U.; Eti, E. Gmelina Arborea Bark Extracts as a Corrosion Inhibitor for Mild Steel in an Acidic Environment. Int. J. Mater. Chem. 2014, 4, 34-39. [CrossRef] 
13. Zheng, X.; Gong, M.; Li, Q.; Guo, L. Corrosion inhibition of mild steel in sulfuric acid solution by loquat (Eriobotrya japonica Lindl.) leaves extract. Sci. Rep. 2018, 8, 9140. [CrossRef] [PubMed]

14. Dehghani, A.; Bahlakeh, G.; Ramezanzadeh, B.; Ramezanzadeh, M. Potential of Borage flower aqueous extract as an environmentally sustainable corrosion inhibitor for acid corrosion of mild steel: Electrochemical and theoretical studies. J. Mol. Liq. 2019, 277, 895-911. [CrossRef]

15. Dehghani, A.; Bahlakeh, G.; Ramezanzadeh, B. A detailed electrochemical/theoretical exploration of the aqueous Chinese gooseberry fruit shell extract as a green and cheap corrosion inhibitor for mild steel in acidic solution. J. Mol. Liq. 2019, 282, 366-384. [CrossRef]

16. Al-Dahiri, R.H. The Application of Zinc Oxide Nanoparticles as An Eco- Friendly Inhibitor for Steel in Acidic Solution. Int. J. Electrochem. Sci. 2020, 15, 442-457. [CrossRef]

17. Khamis, E.A.; Hamdy, A.; Morsi, R.E. Magnetite nanoparticles/polyvinyl pyrrolidone stabilized system for corrosion inhibition of carbon steel. Egypt. J. Pet. 2018, 27, 919-926. [CrossRef]

18. Quadri, T.; Olasunkanmi, L.O.; Fayemi, O.; Solomon, M.M.; Ebenso, E.E. Zinc Oxide Nanocomposites of Selected Polymers: Synthesis, Characterization, and Corrosion Inhibition Studies on Mild Steel in $\mathrm{HCl}$ Solution. ACS Omega 2017, 2, 8421-8437. [CrossRef]

19. Zheng, Y.; Fu, L.; Han, F.; Wang, A.; Cai, W.; Yu, J.; Yang, J.; Peng, F. Green biosynthesis and characterization of zinc oxide nanoparticles using Corymbia citriodora leaf extract and their photocatalytic activity. Green Chem. Lett. Rev. 2015, 8, 59-63. [CrossRef]

20. Rao, M.D.; Gautam, P. Synthesis and characterization of $\mathrm{ZnO}$ nanoflowers usingChlamydomonas reinhardtii: A green approach. Environ. Prog. Sustain. Energy 2016, 35, 1020-1026. [CrossRef]

21. Soto-Robles, C.; Nava, O.; Vilchis-Nestor, A.; Castro-Beltran, A.; Gomez-Gutierrez, C.; Lugo-Medina, E.; Olivas, A.; Luque, P. Biosynthesized zinc oxide using Lycopersicon esculentum peel extract for methylene blue degradation. J. Mater. Sci. Mater. Electron. 2018, 29, 3722-3729. [CrossRef]

22. Al-Snafi, A.E. The chemical constituents and pharmacological effects of Convolvulus arvensis and Convolvulus scammonia-A review. IOSR J. Pharm. 2016, 6, 64-75.

23. Convolvulus. Available online: https://en.wikipedia.org/wiki/Convolvulus (accessed on 17 February 2020).

24. Convolvulus. The Jepson eFlora. Available online: https://ucjeps.berkeley.edu/eflora/eflora_display.php? tid=11474 (accessed on 17 February 2020).

25. Rachitha, P.; Krupashree, K.; Jayashree, G.; Kandikattu, H.K.; Amruta, N.; Gopalan, N.; Rao, M.; Khanum, F. Chemical composition, antioxidant potential, macromolecule damage and neuroprotective activity of Convolvulus pluricaulis. J. Tradit. Complement. Med. 2018, 8, 483-496. [CrossRef] [PubMed]

26. Ngoepe, N.; Mbita, Z.; Mathipa, M.; Mketo, N.; Ntsendwana, B.; Hintsho-Mbita, N. Biogenic synthesis of ZnO nanoparticles using Monsonia burkeana for use in photocatalytic, antibacterial and anticancer applications. Ceram. Int. 2018, 44, 16999-17006. [CrossRef]

27. Ahmed, S.K.; Ali, W.B.; Khadom, A.A. Synthesis and investigations of heterocyclic compounds as corrosion inhibitors for mild steel in hydrochloric acid. Int. J. Ind. Chem. 2019, 10, 159-173. [CrossRef]

28. Fiori-Bimbi, M.V.; Alvarez, P.E.; Vaca, H.; Gervasi, C.A. Corrosion inhibition of mild steel in HCL solution by pectin. Corros. Sci. 2015, 92, 192-199. [CrossRef]

29. Meng, Y.; Ning, W.; Xu, B.; Yang, W.; Zhang, K.; Chen, Y.; Li, L.; Liu, X.; Zheng, J.; Zhang, Y. Inhibition of mild steel corrosion in hydrochloric acid using two novel pyridine Schiff base derivatives: A comparative study of experimental and theoretical results. RSC Adv. 2017, 7, 43014-43029. [CrossRef]

30. Xu, S.; Zhang, S.; Guo, L.; Feng, L.; Tan, B. Experimental and Theoretical Studies on the Corrosion Inhibition of Carbon Steel by Two Indazole Derivatives in HCl Medium. Materials. 2019, 12, 1339. [CrossRef]

31. Ahamad, I.; Prasad, R.; Quraishi, M.A. Thermodynamic, electrochemical and quantum chemical investigation of some Schiff bases as corrosion inhibitors for mild steel in hydrochloric acid solutions. Corros. Sci. 2010, 52, 933-942. [CrossRef]

32. Ahamad, I.; Prasad, R.; Quraishi, M.A. Adsorption and inhibitive properties of some new Mannich bases of Isatin derivatives on corrosion of mild steel in acidic media. Corros. Sci. 2010, 52, 1472-1481. [CrossRef]

33. Ahmed, R.; Farghali, R.; Fekry, A. Study for the Stability and Corrosion Inhibition of Electrophoretic Deposited Chitosan on Mild Steel Alloy in Acidic Medium. Int. J. Electrochem. Sci. 2012, 7, 7270-7282.

34. Izadi, M.; Shahrabi, T.; Ramezanzadeh, B. Active corrosion protection performance of an epoxy coating applied on the mild steel modified with an eco-friendly sol-gel film impregnated with green corrosion inhibitor loaded nanocontainers. Appl. Surf. Sci. 2018, 440, 491-505. [CrossRef] 
35. Usman, B.J.; A Umoren, S.; Gasem, Z.M. Inhibition of API 5L X60 steel corrosion in $\mathrm{CO}_{2}$-saturated $3.5 \% \mathrm{NaCl}$ solution by tannic acid and synergistic effect of KI additive. J. Mol. Liq. 2017, 237, 146-156. [CrossRef]

36. Ituen, E.; Akaranta, O.; James, A. Evaluation of Performance of Corrosion Inhibitors Using Adsorption Isotherm Models: An Overview. Chem. Sci. Int. J. 2017, 18, 1-34. [CrossRef]

37. Sophie, P.; Anthony, N. Kinetic, Thermodynamic and Adsorption Studies for Corrosion Inhibition of Carbon Steel by Asparagaeus Setaceus L. $+\mathrm{Mn}^{2+}$ in Neutral Media. Int. J. Res. Appl. Sci. Eng. Technol. 2018, 6, 3125-3133. [CrossRef]

38. Santos, É.D.C.D.; Cordeiro, R.; Dos Santos, M.; Rodrigues, P.R.P.; Singh, A.; D’Elia, E. Barley Agro-industrial Residues as Corrosion Inhibitor for Mild Steel in 1mol L-1HCl Solution. Mater. Res. 2019, 22. [CrossRef]

39. Saha, S.K.; Dutta, A.; Sukul, D.; Ghosh, P.; Banerjee, P. Adsorption and corrosion inhibition effect of Schiff base molecules on the mild steel surface in $1 \mathrm{M} \mathrm{HCl}$ medium: A combined experimental and theoretical approach. Phys. Chem. Chem. Phys. 2015, 17, 5679-5690. [CrossRef]

40. Verma, C.; Quraishi, M.A. Adsorption behavior of 8,9-bis(4 (dimethyl amino)phenyl)benzo[4,5] imidazo[1,2-a]pyridine-6,7-dicarbonitrile on mild steel surface in $1 \mathrm{M} \mathrm{HCl}$. J. Assoc. Arab. Univ. Basic Appl. Sci. 2017, 22, 55-61. [CrossRef]

41. Raja, A.S.; Rajendran, S.; Satyabama, P. Inhibition of Corrosion of Carbon Steel in Well Water by DL-Phenylalanine-Zn ${ }^{2+}$ System. J. Chem. 2012, 2013, 720965. [CrossRef]

42. Essien, E.A.; Kavaz, D.; Ituen, E.; A Umoren, S. Synthesis, characterization and anticorrosion property of olive leaves extract-titanium nanoparticles composite. J. Adhes. Sci. Technol. 2018, 32, 1773-1794. [CrossRef]

43. Singh, P.; Chauhan, D.; Srivastava, K.; Srivastava, V.; Quraishi, M. Expired atorvastatin drug as corrosion inhibitor for mild steel in hydrochloric acid solution. Int. J. Ind. Chem. 2017, 8, 363-372. [CrossRef]

(C) 2020 by the author. Licensee MDPI, Basel, Switzerland. This article is an open access article distributed under the terms and conditions of the Creative Commons Attribution (CC BY) license (http://creativecommons.org/licenses/by/4.0/). 